\title{
Capillary-based method for rock typing in transition zone of carbonate reservoirs
}

\author{
Jalal Dakhelpour-Ghoveifel ${ }^{1} \cdot$ Morteza Shegeftfard $^{1} \cdot$ Morteza Dejam $^{2}$
}

Received: 2 August 2018 / Accepted: 23 November 2018 / Published online: 30 November 2018

(c) The Author(s) 2018

\begin{abstract}
Reservoir simulation is established as a good practice to make the best decision for a petroleum reservoir. The reservoir is characterized in terms of reservoir elements such as structural model, well data, rock and fluid properties. Then the reservoir model is enhanced through history matching and finally different prediction scenarios are tried to find the best plan for the reservoir understudy. The more accurate the reservoir is characterized, the faster and the more precisely the history match is finished and the more reliable predictions are obtained. The most important part of reservoir characterization is the rock typing, where the quality of CCAL (conventional core analysis) and SCAL (special core analysis) properties are evaluated and estimated for any simulation grid. The resulting oil in place must be confirmed by the OOIP (original oil in place) calculated based on average petro-physical parameters for any layer. To allocate different rock types to simulation grid, rock types should be assigned according to different ranges of rock differentiation parameter which has to be determined in any specific study. Based on our experience in Iranian carbonate reservoirs, most frequently irreducible water saturation is the rock differentiation parameter. In the oil zone, water saturation from log data is assumed to be the irreducible water saturation. Thus, the rock type is identified with no trouble. The problem arises in transition zone, where water saturation from $\log$ data is not equal to the irreducible water saturation of that rock. This study includes the observed variations in terms of water saturation data versus depth and how to assign rock types to the transition zone grids. The objective of the capillarybased method is to produce a water saturation map which honors laboratory data as well as the well log data and considers the depth so that it can handle the transition zone in a proper manner. In fact, novelty of this work is to explain how it is possible to consider log and capillary pressure data together so that the most accurate rock type is assigned to reservoir grids of the transition zone. Moreover, this method is consistent with equilibration method for initializing reservoir simulations. A procedure is presented for how to implement the capillary-based method in a stepwise manner. Once the proposed method is carried out, the initialized simulation model is consistent with all sources of data (core analysis and petro-physical data). In this procedure original oil in place calculated after the initialization for simulation is more accurate and can be crosschecked with volumetric calculation based on interpreted log data. Therefore, it is considered to facilitate subsequent stages of reservoir study, namely history match and prediction.
\end{abstract}

Keywords Reservoir simulation $\cdot$ Rock typing $\cdot$ Carbonate rocks $\cdot$ Transition zone $\cdot$ Capillary

$\begin{array}{ll}\text { List of } & \text { symbols } \\ g & \text { Gas } \\ K & \text { Permeability }\end{array}$

Morteza Dejam

mdejam@uwyo.edu

1 Reservoir Studies Division, Department of Petroleum Engineering, National Iranian South Oil Company (NISOC), Ahvaz, Iran

2 Department of Petroleum Engineering, College of Engineering and Applied Science, University of Wyoming, 1000 E. University Avenue, Laramie, WY 82071-2000, USA
$K_{\mathrm{r}} \quad$ Relative permeability

$K_{\text {rdn }} \quad$ Denormalized relative permeability

$K_{\text {r-max }}$ Maximum relative permeability

$K_{\text {r-min }} \quad$ Minimum relative permeability

$K_{\text {rn }} \quad$ Normalized relative permeability

$l \quad$ Liquid

$o \quad$ Oil

$P_{\text {cdn }} \quad$ Denormalized capillary pressure

$P_{\text {c-max }} \quad$ Maximum capillary pressure

$P_{\text {c-min }} \quad$ Minimum capillary pressure

$\mathrm{P}_{\mathrm{cn}} \quad$ Normalized capillary pressure

$S_{\text {wdn }} \quad$ Denormalized water saturation 
$S_{\text {wirr }} \quad$ Irreducible water saturation

$S_{\text {w-max }}$ Maximum water saturation

$S_{\text {w-min }}$ Minimum water saturation

$\mathrm{S}_{\mathrm{wn}} \quad$ Normalized water saturation

$w \quad$ Water

$\Delta G_{w o} \quad$ Water gradient - oil gradient

$\Delta H \quad$ Free water level - grid depth

$\phi \quad$ Porosity

\section{Introduction}

To produce hydrocarbon in an optimized manner, it is necessary to have a comprehensive knowledge of rocks and fluids in reservoir conditions. Representing a correct description of reservoir rock characteristics in addition to fluid properties is considered as the basis of reservoir engineering studies. In fact, one of the major tasks in reservoir simulation is rock typing.

Reservoir rock types are critical factors in reservoir characterization and one of the most challenging subjects in carbonate reservoirs. A goal of reservoir rock typing is to identify hydraulic units that have similar fluid flow properties (Bize-Forest et al. 2014).

It is very important to classify the rock types because they show different behavior in the presence of different fluids. The rock typing definition was first introduced by Archie who classified carbonate rocks according to grain type and apparent porosity (Archie 1952). There are various definitions for carbonate rock classification and petrographical identification. Geologists define rock units according to the volume of the rock that represents similar sedimentary and diagenetic conditions (Gomes et al. 2008). Since the capillary pressure curves are the direct result of structure and geometry of pore size and throats, for proper classification, one has to pay special attention to lithology. For this reason, cores were classified according to their rock type and petro-physical characteristics into limestone, dolomite, and sandstone. Permeability and porosity of reservoir rock considered as the most important parameters for evaluation and estimation of reservoir (Shedid and Almehaideb 2002). Ubani et al. (2012) focused on porosity, storage capacity for reservoir fluids, permeability, reservoir flow capacity, as well as fluid saturation, fluid type and content.

Petro-physically speaking, the rock unit is that volume of the rock that represents similar petro-physical reaction in the well profile (Amaefule et al. 1993; Noorddin et al. 2011). Different rock types are identified by integrating petro-physical data with core description information using multi-variate statistical methods (Askari and Behrouz 2011). However, from reservoir engineering point of view, the rock unit is considered as the volume of rock in which the distribution of pore sizes, capillary pressures and relative permeabilities are similar. In sandstone reservoirs, a hydraulic flow unit can generally be considered as a part of the reservoir where specific petro-physical and geological properties are the same and, therefore, capillary pressure and relative permeability are similar. (Noorddin et al. 2011; Svirsky et al. 2004).

Permeability and porosity are always considered as two major parameters in reservoir evaluation and determination of rock characteristics. The FZI (flow zone indicator) method utilizes a combination of those properties to do the rock typing. Then, according to previous stage classification, the results from SCAL tests are assigned to different rock types. A very popular task to perform the rock typing is to combine the FZI method with the porosity log and the prediction of permeability as a synthetic log (Ghadami et al. 2015; Riazi 2018). Moradi et al. (2017) added more detailed geological description to get a more accurate model.

Also for rock typing, we can use the results from SCAL tests carried out on core samples. The results should be used as a part of input data in reservoir simulator. Thus, the accuracy of simulations directly depends on the quality of SCAL tests. Different rock types are assigned to separated intervals of a rock differentiation parameter based on SCAL tests. In conjunction with CCAL properties, thin sections and hand samples are investigated to encounter pore geometry, pore connectivity and the influence of diagenesis in the pore system to classify rock types (Tonietto et al. 2014). Micro-CT and micro-X-ray fluorescence systems are combined to obtain information on spatial distribution of chemical elements in a rock (Mutina and Bruyndonckx 2012). In this approach, mineralogy is also considered in the process of rock typing. Mirzaei-Paiaman et al. (2018) combined Kozeny-Carman equation with Darcy's law and

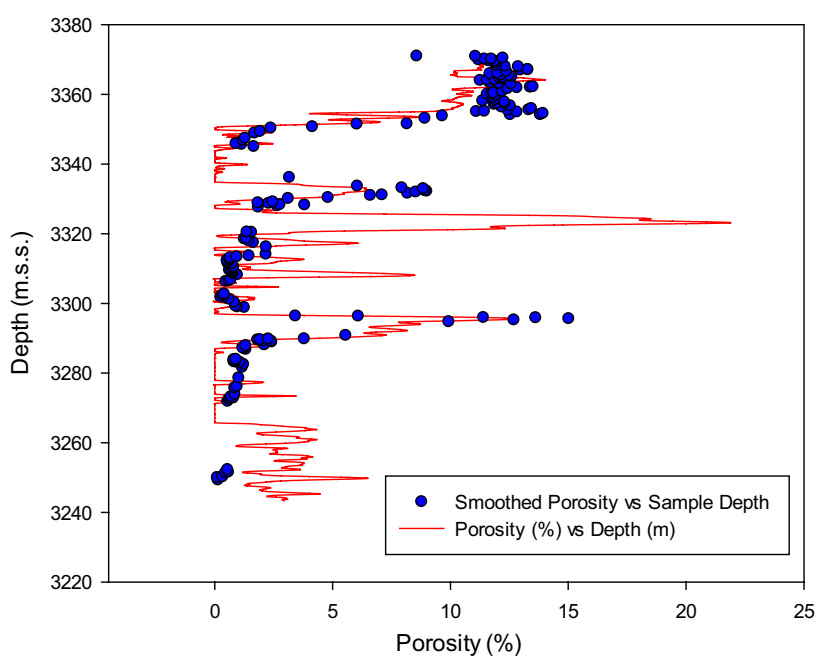

Fig. 1 Depth match of porosity from core and log data. This is plotted to certify well log interpretation along with CCAL test results 
Young-Laplace capillary pressure expression to modify the J-function correlation, which can normalize capillary pressure data universally. Beside simulation, deduction of the rock types before SCAL tests may be useful in sample selection for this sort of tests. Attempts have been made to use rock types in sample selection process (Mirzaei-Paiaman and Saboorian-Jooybari 2016; Siddiqui et al. 2003, 2006). Recently, Lian et al. (2016) have used the idea of capillary height to build three dimensional map of water saturation. A similar approach is adapted in this work. The difference between Lian et al. (2016) work and this study is the rock type, which is the main unknown in modeling and simulation.

In this study, SCAL tests have been carried out and relative permeability and capillary pressure curves are obtained for some cores. Analysis includes 26 samples of capillary pressure and 25 relative permeability measurements. Capillary pressure curves using centrifugal method for both drainage and imbibition cycles were obtained. The capillary pressure curves show a wide range of variations indicating different pore geometries and reservoir properties.

At the first step, for controlling the data quality resulted from log and cores, it is recommended to compare CCAL test results with petro-physical evaluation of porosity (through depth matching). Porosities from core and log data are compared in Fig. 1.

Usually abundant amount of log data are available. Therefore, the common practice in the industry is to find a relation between petro-physical parameters (water saturation and porosity) and the type of rocks. Petro-physical data can be distributed in reservoir model grids using geo-statistic methods. Rock differentiation parameter can be defined based on petro-physical data as well. Rock type is assigned to each grid on the basis of some ranges for petro-physical parameters intervals.
In some studies, irreducible water saturation is selected as rock differentiation parameter. In that case, it is possible to provide some fix ranges for rock differentiation in the oil zone, which is a common practice in the industry. However, $\log$ data do not show the irreducible water saturation in transition zone.

Figure 2 shows a sketch of rock typing with fixed ranges of irreducible water saturation, where point $\mathrm{A}$ is classified as rock type 4 incorrectly. This will lead to underestimating the oil in place, because through initialization stage of simulation, water saturation will be assigned based on rock type 4 (about $80 \%$ ) instead of the correct value of $30 \%$. The method mentioned in this paper will classify this point in rock type 1 .

In the proposed capillary-based method for rock typing, the intervals separating the rock types are not fixed in the transition zone. Modifying these intervals as a function of

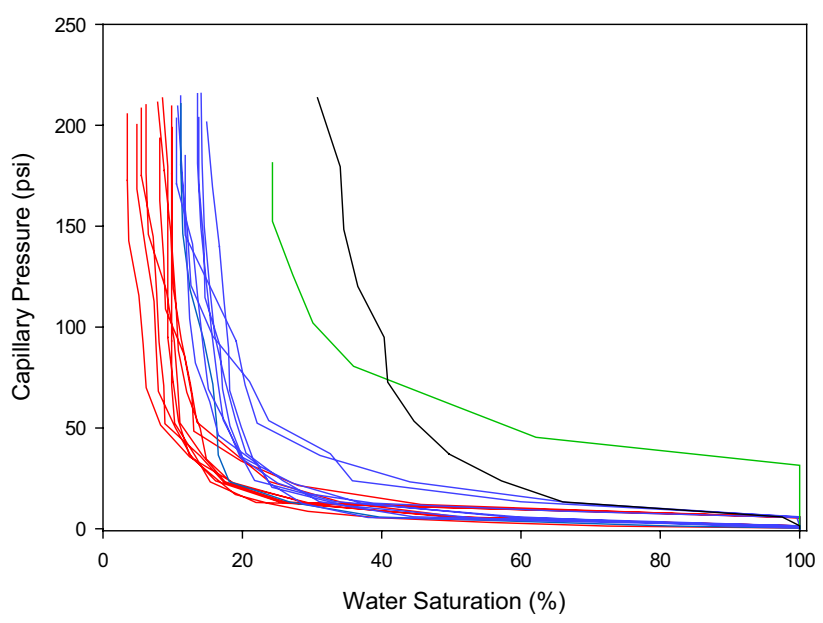

Fig. 3 Separation of capillary pressure curves for different rock types
Fig. 2 Sketch of rock typing with fix ranges of irreducible water saturation. Point "A" located in the transition zone must be classified as rock type 1 rather than rock type 4

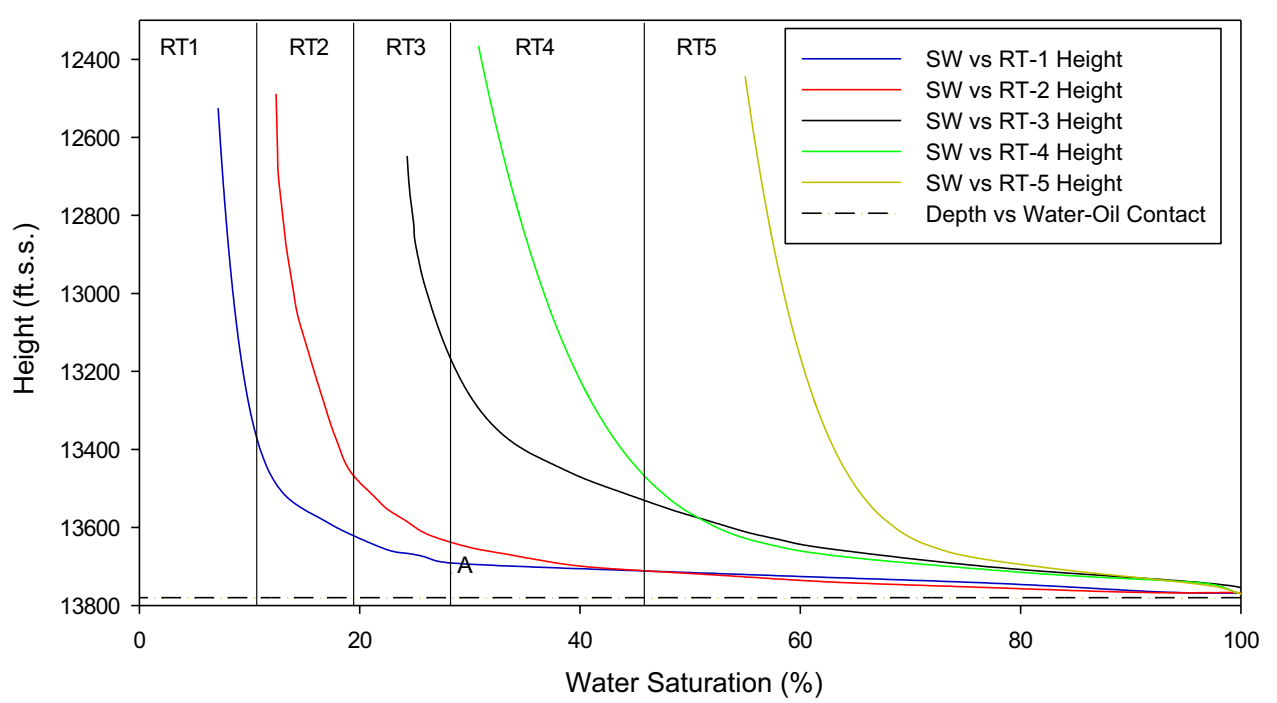

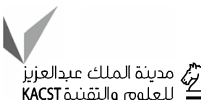
Springer 
depth can resolve the mentioned problem. Not following the mentioned procedure gives poor results in reservoirs with a large transition zone. Specifically, imbibition will happen much weaker and WOC will rise very fast because both rock type and OOIP in grids of transition zone are worse than the reality of the field. Besides, recovery factor for rock type 4 is less than that of rock type 1 , which will result in pessimistic estimation of recovery factor.

First, reservoir rock typing is presented. Then capillary pressures of water-oil and gas-oil drainage and imbibition processes are described. Thereafter, water-oil and gas-oil relative permeabilities are explained. Next, the capillarybased method for allocation of different rock types into a simulation grid is proposed. The method is based on the use of data from logs and capillary pressure and the aim is to give a good characterization to the transition zone which is the main objective of this work, and finally conclusions and summary are presented.

\section{Reservoir rock typing}

To classify samples of the reservoir rock, drainage water-oil capillary pressure curves are usually used. Since the form of the capillary pressure curves may serve as an indication of basic parameters of a rock, such as rock permeability, homogeneity, pore radius, and rock wettability, this form can describe rock drainage under the governing mechanism. It can be generally assumed that rocks of similar capillary pressure curves exhibit the same behavior in terms of fluid flow. Therefore, to determine different types of reservoir rocks, one can draw all of the water-oil capillary pressure curves on the same plot and classify similar curves under the same class. Figure 3 presents the separation of capillary pressure curves for different rock types.

After plotting the capillary pressure curves in the same coordinates and assigning a reservoir rock type index to each sample, a rock differentiation parameter is to be introduced such that different rock types lay in separated intervals of the parameter.

In this method, rock typing is based on the form of capillary pressure curves and, particularly, corresponding residual water saturations. Considering the form of the capillary pressure curves, one can see that the curves exhibit mostly similar trends and curvatures in different ranges of initial water saturation. Considering this behavior and the fact that the samples in the same class should be close to one another in terms of residual water saturation, the rock differentiation parameter should be selected in such a way that capillary pressure curves in each rock type are close to one another in terms of residual water saturation of the samples, that is, residual water saturation of samples serve as an important criterion considered for selecting the differentiation parameter.

Practically, most of the time, there are too much samples to find a property to define exact borders between the rock types. Therefore, using any differentiation parameter maybe a minority of data are abandoned.

Carbonated rocks are usually heterogeneous. Besides, sometimes the samples are too few to use sophisticated methods such as facies modeling. In that case, the only option is to find a combination of petro-physical parameters which is capable of differentiating the rock types.
Fig. 4 Differentiation of irreducible water saturation in terms of porosity. No differentiation is performed using porosity for porosity values of more than $8 \%$ because irreducible water saturation is not decreasing

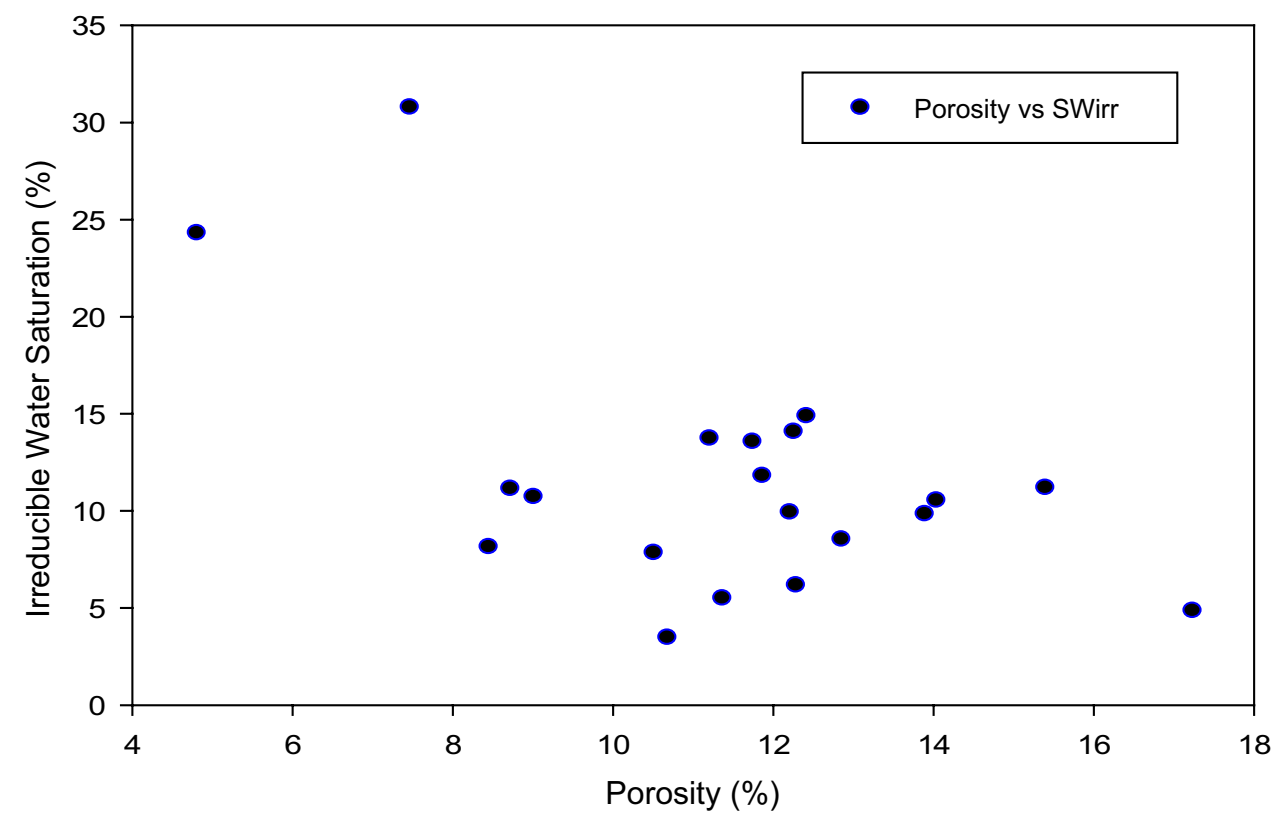


As the first step, porosity, as an independent parameter which is measured directly on petro-physical logs (which makes it the best choice, if possible), was considered to check the differentiation between capillary pressure curves (Fig. 4).

At first glance, it seemed that a decreasing relationship exists between different data points, so that the differentiation can be performed. However, further investigations considering water saturation development across the reservoir, in petro-physical logs showed that to come up with adequate differentiation, one should drop some $50 \%$ of the samples from the investigations. With no reason for omitting such a large number of data points, this omission could not be accepted.

Having finished with considering the porosity, different parameters together with their combinations were taken into consideration. The permeability parameter may not be obtained independently within the reservoir extensions; in a simulation model, it is rather either propagated as a function of porosity or developed by generating synthetic logs using neural network-based methods which are associated with some uncertainties.

Of the most important relationships and parameters considered for adequately differentiating the curves, one may refer to the following:

$\phi, K, S_{w}, S_{w} \phi$,

$S_{w}|\ln \phi|, K \phi, \frac{\phi}{S_{w}}, \frac{K}{\phi}, \frac{K}{S_{w} \phi}, S_{w} \frac{K}{\phi}$,

$\left(1-S_{w}\right) \frac{K}{\phi}, \sqrt{\frac{K}{\phi}}, S_{w} \sqrt{\frac{K}{\phi}},\left(1-S_{w}\right) \sqrt{\frac{K}{\phi}}$.

Among the above items, a discussion was previously presented on porosity, and except for water saturation, product of water saturation by porosity, and product of water saturation by absolute value of the logarithm of porosity, other items returned totally unacceptable differentiations.

Due to its nature, product of water saturation by porosity cannot serve as a good expression for differentiating the rock types in the model, because the cases with low porosity possess high water saturation and those with high porosity

Table 1 Reservoir rock classes according to the water saturation hold low water saturation (as an example, a point with porosity and water saturation of $4 \%$ and $60 \%$, respectively, and another point with porosity and water saturation of $12 \%$ and $20 \%$, respectively) fall within the same range when the result of this relationship is concerned.

This case may be less visible for the tested rock samples used to determine the relationship, because of limited number of the experiments and failure to cover all ranges of reservoir porosity and water saturation, but it is highlighted when distributing rock type classes across the reservoir model due to the presence of all petro-physical data, different types of good and bad reservoir rocks are prone to erroneous classification in the same class. On the other hand, the large number of omitted samples or weaker differentiation of the product of water saturation by porosity kept us from selecting this expression.

Both of the remaining expressions mentioned (water saturation and product of water saturation by absolute value of the logarithm of porosity) exhibited identical differentiation of the tested samples. As such, since the logarithm of porosity represents no particular physical concept and considering the fact that its application is basically associated with no improvement in sample differentiation, but rather adds the associated uncertainty with the porosity to that of water saturation, as a final conclusion, residual water saturation was selected to serve as reservoir rock differentiation parameter.

Eventually, reservoir rock samples were divided into four classes according to laboratory data tabulated in Table 1. In the laboratory, irreducible water saturation is reported. However, irreducible water saturation is not reached in the transition zone. The rock typing method mentioned in this paper will provide a solution to determine the rock types in the transition zone.

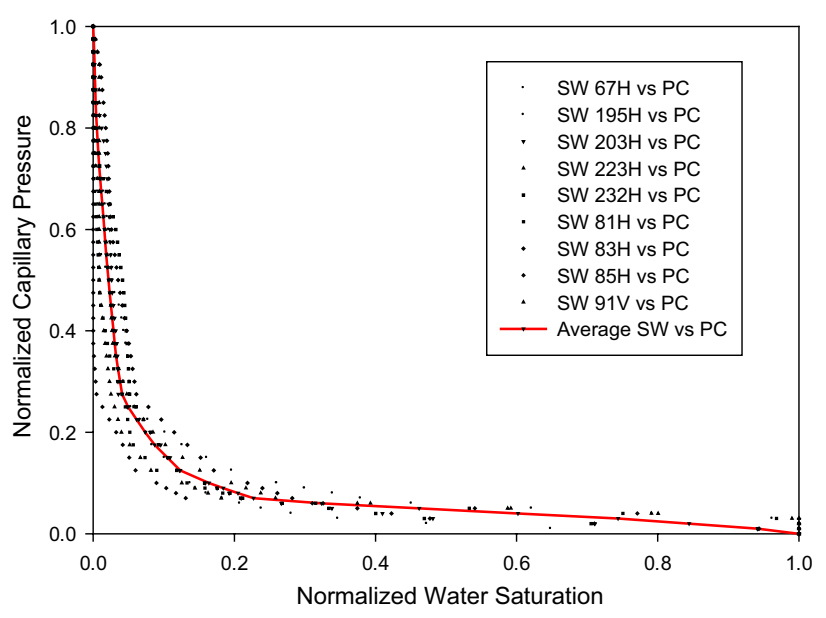

Fig. 5 Normalized capillary pressure versus normalized water saturation for rock type 1 . Sample showing the process of averaging normalized curves

\begin{tabular}{ll}
\hline Rock type & $\begin{array}{l}\text { Rock differen- } \\
\text { tiation parameter } \\
\text { range }\end{array}$ \\
\hline RT-1 & $0 \leq$ Swirr $<0.1$ \\
RT-2 & $0.1 \leq$ Swirr $<0.2$ \\
RT-3 & $0.2 \leq$ Swirr $<0.3$ \\
RT-4 & $0.3 \leq$ Swirr $<0.4$ \\
RT-5 & $0.4 \leq$ Swirr \\
\hline
\end{tabular}

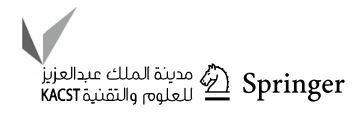


It is worth noting that, in the course of rock type determination across the considered field using water-oil capillary pressure curves, the transformation of capillary pressure curves to the corresponding J-Functions was later utilized, but it also failed to impose any positive contribution to sample differentiation. Of course, this failure was predictable considering unchanged endpoints (residual water saturation) of the curves, following the transformation of the capillary pressure curves to J-Function, when bearing in mind the importance of this parameter in sample differentiation.

\section{Capillary pressures of water-oil drainage process}

To obtain average capillary pressure curves for water-oil drainage process in each rock type, the plots related to the samples were drawn separately and normalized to $[0,1]$ (Fig. 5). Data normalization was performed using the following relationships:

$S_{\mathrm{wn}}=\frac{\left(S_{\mathrm{w}}-S_{\mathrm{w}-\min }\right)}{\left(S_{\mathrm{w}-\max }-S_{\mathrm{w}-\min }\right)}$,

$P_{\mathrm{cn}}=\frac{\left(P_{\mathrm{c}}-P_{\mathrm{c}-\min }\right)}{\left(P_{\mathrm{c}-\max }-P_{\mathrm{c}-\min }\right)}$,

where " $P_{\mathrm{c}}$ " and " $S_{\mathrm{w}}$ " stand for capillary pressure and water saturation, respectively. Subscript "N" stands for normalized properties. Once the data were normalized, average values of normalized plots were plotted for each class of rocks. Then the endpoint of the capillary pressure curve for water-oil drainage was calculated for each class of rocks. These points included residual water saturation or initial water saturation for each class of rocks, maximum capillary pressure to reach such a water saturation, and threshold capillary pressure for oil to enter the rock. Following the distribution of different rock types in the model, the initial water saturation determined for each class of rocks will directly affect oil in place of the simulation model.

Table 2 Values obtained for endpoints of the capillary pressure curves for water-oil drainage process

\begin{tabular}{llll}
\hline Rock type & $\begin{array}{l}\text { Irreducible water } \\
\text { saturation (fraction) }\end{array}$ & $\begin{array}{l}\text { Threshold } \\
\text { pressure (psi) }\end{array}$ & $\begin{array}{l}\text { Maximum capil- } \\
\text { lary pressure (psi) }\end{array}$ \\
\hline RT-1 & 0.071 & 1.838 & 205.73 \\
RT-2 & 0.124 & 2.04 & 206.69 \\
RT-3 & 0.243 & 4.739 & 181.21 \\
RT-4 & 0.308 & 1.483 & 226.33 \\
RT-5 & 0.55 & 1.483 & 213.87 \\
\hline
\end{tabular}

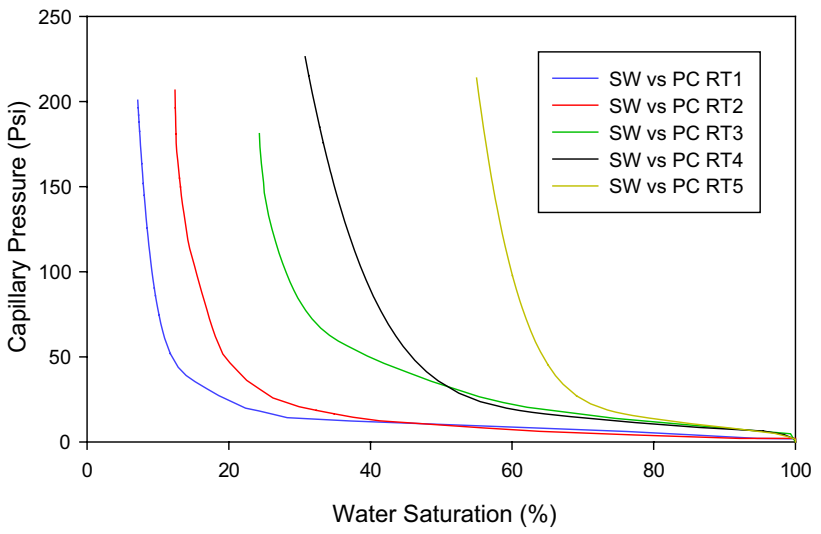

Fig. 6 Average capillary pressure curves of water-oil drainage process for different classes of rocks

This is because the water saturation distributed in model cells using well petro-physical data and geo-statistical techniques will be replaced by the water saturation obtained from the average capillary pressure curve of water-oil drainage process. Therefore, in the simulation grids, to get the same OOIP as the volume calculation based on petro-physical data, average residual water saturation for the capillary pressure curve was calculated using petro-physical logs.

For this purpose, interpreted petro-physical data along the wells drilled above the transition zone were segmented based on the ranges determined for the generalized parameter, and average water saturation over each segment was calculated using porosity as weight factor. This average is considered to be representative residual water saturation for the corresponding rock class. To determine threshold capillary pressure and maximum capillary pressure applied to each class, arithmetic averaging was conducted on different values obtained for different samples in each class of rocks.

Table 2 presents the values obtained for endpoints of the capillary pressure curves for water-oil drainage process. In the next step, the normalized curves were denormalized to the obtained endpoints using the following relationships:

$S_{\mathrm{wdn}}=S_{\mathrm{wn}}\left(S_{\mathrm{w}-\max }-S_{\mathrm{w}-\text { min }}\right)_{\mathrm{new}}+\left(S_{\mathrm{w}-\mathrm{min}}\right)_{\mathrm{new}}$,

$P_{\text {cdn }}=P_{\text {cn }}\left(P_{\text {c-max }}-P_{\text {c-min }}\right)_{\text {new }}+\left(P_{\text {c-min }}\right)_{\text {new }}$,

where subscript "DN" and "new" denote denormalized properties and the average endpoints calculated for SW or PC, respectively. Figure 6 shows final capillary pressure curves of water-oil drainage process for different classes of rocks across the field understudy. 


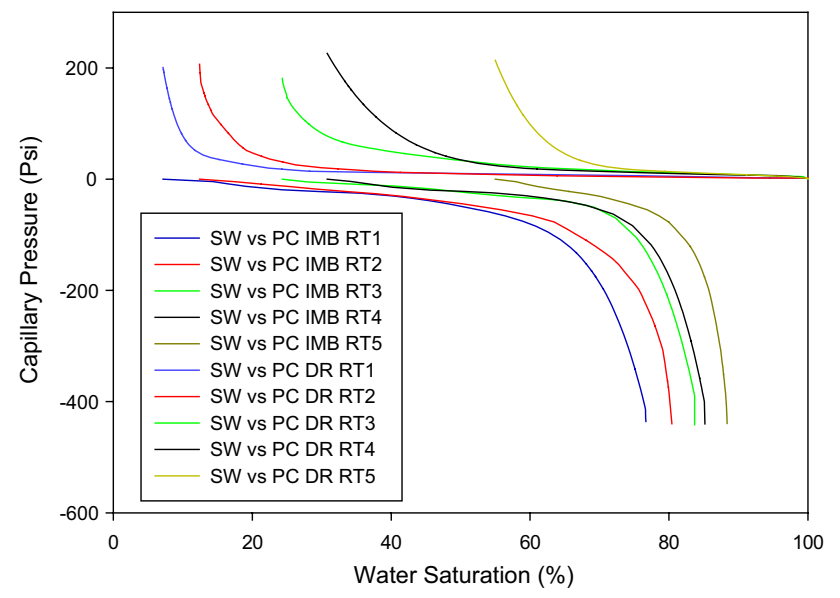

Fig. 7 Capillary pressure curves for water-oil imbibition process along with drainage curves

\section{Capillary pressure of water-oil imbibition process}

To obtain the average capillary pressure curve for water-oil imbibition process in different rock types, corresponding curves to samples in each class were drawn separately, and as mentioned for the drainage process, the curves were normalized to $[0,1]$ with respect to water saturation and capillary pressure, and arithmetic average values were then calculated for each class of rocks.

In the next step, endpoints of the capillary pressure curves of water-oil imbibition process were determined for each class of rocks by averaging the endpoints of the corresponding capillary pressure curves. Initial water saturation for each class of rocks was set to the initial saturation calculated in the capillary pressure curves of water-oil drainage process for any class of rocks.

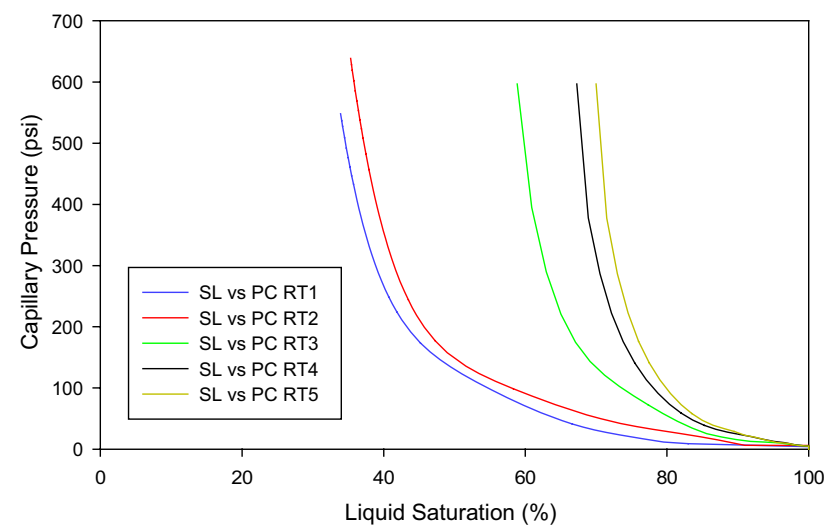

Fig. 8 Capillary pressure curves for gas-oil drainage process
Moreover, the threshold pressure for each class of rocks was set to the average value of threshold pressures of the samples in that class. Figure 7 presents capillary pressure curves for water-oil imbibition process along with drainage curves.

\section{Capillary pressure of gas-oil drainage process}

To obtain capillary pressure curve for gas-oil drainage process in different rock types determined, corresponding curves to samples were drawn for each class separately, and as mentioned above, the capillary pressure curves were normalized to $[0,1]$ with respect to liquid saturation (oil plus connate water); average values were then calculated for each class of rocks.

In the next step, endpoints of the capillary pressure curves of gas-oil drainage process (threshold pressure, maximum capillary pressure, and residual liquid saturation) were determined for each class of rocks by averaging the endpoints of the corresponding curves. Residual oil saturation in gas-oil drainage process is calculated considering the initial water saturation at capillary pressures of water-oil drainage process and residual liquid saturation determined for each class of rocks.

Once the endpoints are determined, average normalized curves are denormalized to the obtained saturations and pressures. Figure 8 presents capillary pressure curves for gas-oil drainage process.

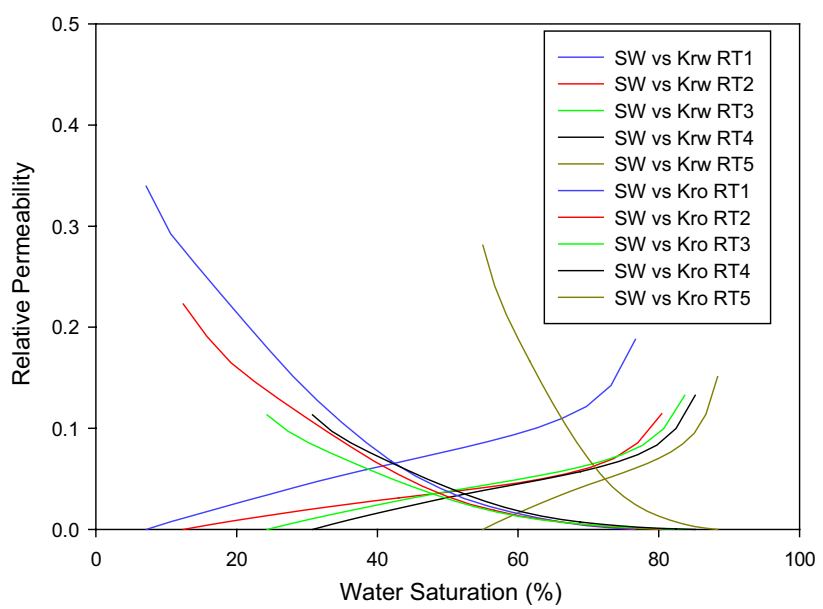

Fig. 9 Relative permeability curves in water-oil system

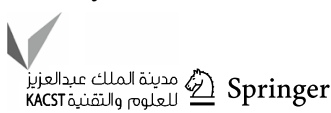




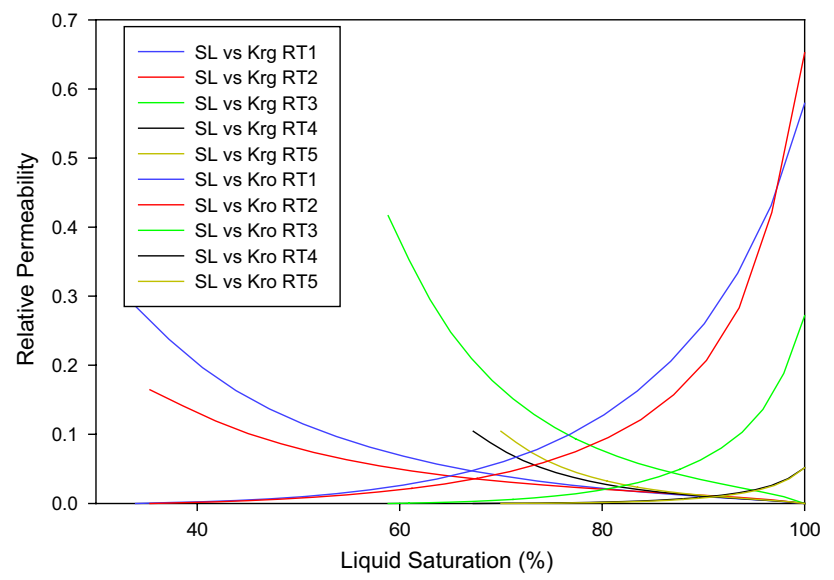

Fig. 10 Relative permeability curves in gas-oil system

\section{Water-oil and gas-oil relative permeability}

First, water saturation and relative permeabilities of water and oil in water-oil system, and also liquid saturation and relative permeabilities of gas and oil in gas-oil system were normalized to $[0,1]$. The following relationship was used for the relative permeabilities:

$K_{\mathrm{rn}}=\frac{\left(K_{\mathrm{r}}-K_{\mathrm{r}-\min }\right)}{\left(K_{\mathrm{r}-\max }-K_{\mathrm{r}-\min }\right)}$,

where " $K_{\mathrm{r}}$ " stands for relative permeability and subscript "N" stands for normalized property. Once the normalized curves were averaged for each class of rocks, endpoints of relative permeabilities, including relative permeability of oil at initial water saturation and relative permeability of water at residual oil saturation in water-oil system, and also relative permeability of oil at zero gas saturation and relative permeability of gas at residual oil saturation in gas-oil system were calculated by averaging the corresponding values to the samples in each class of rocks. Values of fluid saturations at endpoints of the curves of each class of rock were set to the calculated values of these parameters along capillary pressure curves. Afterwards, the normalized average curves in each class were denormalized to the endpoints of saturation and relative permeability of that class. The following relationship was used to denormalize the relative permeabilities:

$K_{\text {rdn }}=K_{\text {rn }} \times K_{\text {r-max }}$,

where subscripts "DN" and "N" stand for denormalized and normalized relative permeabilities. Relative permeability curves in water-oil and gas-oil systems are demonstrated in Figs. 9 and 10, respectively.

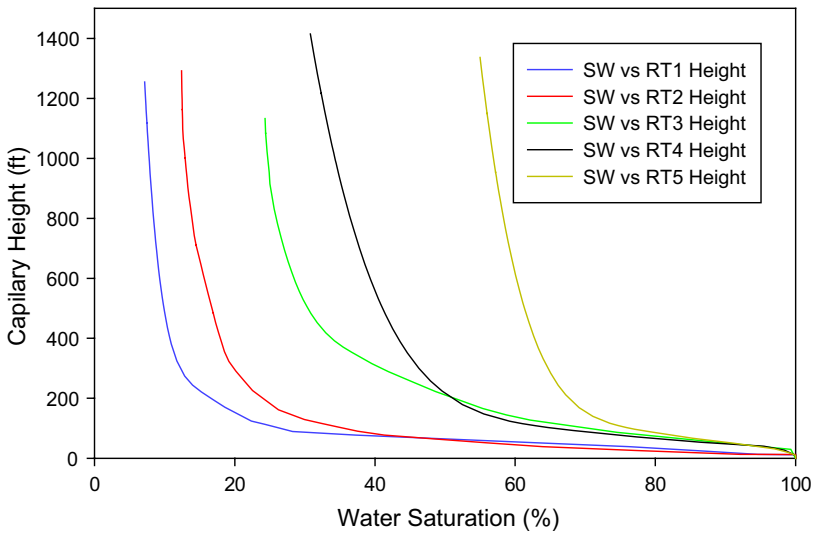

Fig. 11 Average capillary height curves of water-oil drainage process for different classes of rocks. This figure is derived from Fig. 6 by Eq. (7)

\section{Assigning rock type index to simulation grid}

As mentioned above, the problem with using water saturation as the rock development parameter arises in the transition zone, where the water saturation interpreted from the well logs is not the irreducible water saturation. The capillary pressure data in this reservoir show a good correlation between rock types and the irreducible water saturation. In this work, the algorithm for assigning the rock types to the grids is proposed.

So far, we have come up with an average of capillary pressure curve versus water saturation for each rock type as shown in Fig. 6. We can use the following equation to change capillary pressure into depth of the grids:

$P_{\mathrm{c}}=\Delta G \times \Delta H$,

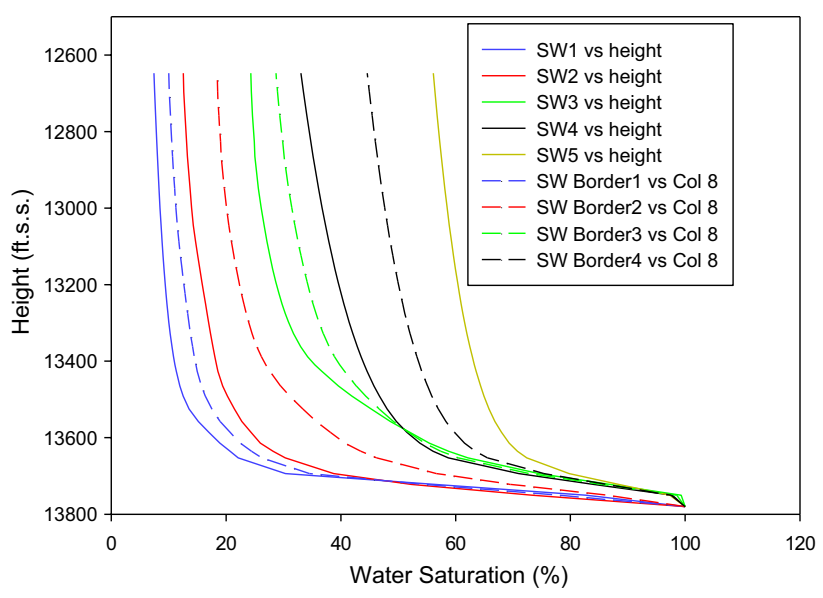

Fig. 12 Borders between different classes of rocks in capillary height curve plot. The borders are calculated as a function of depth using mentioned procedure 
where $\Delta G$ is the difference between oil and water gradients and $\Delta H$ is the difference between the grid depth and the free water level.

Therefore, Fig. 6 changes into Fig. 11. Now we specify border curves, shown as broken lines in Fig. 12 which separate different rock types in terms of the grid depth and the grid water saturation. We need to find the equation to calculate water saturation of all borders as a function of depth. Water saturation range of each rock type as a function of depth has to be calculated first. The following equation gives the border water saturation as a function of depth:

$S w($ border $i)=0.5 \times[S w($ Rock-Type $i)+S w($ Rock-Type $i+1)]$,

where subscript border $i$ stands for border for rock type $i$ and $\mathrm{Sw}_{\text {(rock type } i \text { ) }}$ and $\mathrm{Sw}_{(\text {rock type } i+1)}$ are the average water saturations for rock type $i$ and $i+1$, respectively. Water saturation must be distributed in the reservoir grids using geo-statistics. Next, water saturation for each grid should be compared with the border saturations. If water saturation of the grid is between water saturations of border $i$ and $i+1$ then the grid belongs to rock type $i+1$.

The main idea is that the saturation variations as a function of depth (especially in the transition zone) are manipulated comprehensively. These variations are observed in well logs as well and they can be distributed in the reservoir.

It is worth to mention here that using geo-statistic technics may cause higher values of water saturation to be distributed in the deeper cells of the reservoir, that is, the effect of higher water saturation observed in the transition zone of the well logs will be distributed in the reservoir grids of the reservoir transition zone as well.

Reservoir characterization phase of any project comprises rock and fluid analyses. In simulation phase, a value is assigned to each grid of the model, but there is no guarantee that this is exactly the case in that specific reservoir.

Based on our experience in Iranian southwest carbonated reservoirs, methods using routine data such as FZI (which do not consider water saturation) cannot separate drainage capillary pressure curves. In addition, abundant water saturation data are available from well logs. If SW or any combination of SW and other parameters such as porosity can discretize different rock types, the procedure suggested in this paper may be applied. This is the application of this study. For instance, if porosity is the rock differentiation parameter, then this method is not to be implemented.

The advantage of this study is to include the observed variations in terms of water saturation data. The justification in this study is to produce a realization which honors laboratory data as well as the well log data and considers the depth so that it can handle the transition zone in a proper manner. Moreover, this method is consistent with equilibration method for initializing reservoir simulations. The method can be implemented by the user in simulation pre-processors such as Petrel and RMS as follows:

1. Distribute SW from petro-physical interpretation in the reservoir grids.

2. Estimate the dash lines in Fig. 12 by equations that show the boundaries between rock types as a function of depth (i.e., boundary1, boundary $2, \ldots$ ).

3. Assign all the boundaries to all the grids.

4. Assign rock types using "if" statements such that in the "if condition" water saturation is compared with the boundary values.

\section{Conclusion and recommendation}

SCAL data for an Iranian petroleum reservoir are clustered and different parameters have been checked to find the best rock differentiation parameter.

Based on SCAL data the rock differentiation parameter in this reservoir is irreducible water saturation.

Abundant amount of water saturation data are available from well logs. In the oil zone, it can be assumed that water saturation from logs is the irreducible water saturation but in the transition zone this assumption is not valid.

In the capillary-based method, the rock type index is assigned by comparing water saturation distributed in the grids with the borders between capillary height of different rock types.

This procedure is consistent with the equilibration method for initializing reservoir simulations.

The method can be implemented by the user in simulation pre-processors such as Petrel and RMS.

A procedure is presented in a stepwise manner.

Not going through the procedure while using irreducible water saturation as the rock differentiation parameter will lead to pessimistic estimation of recovery factor of imbibition in the transition zone.

The capillary-based method of rock typing can be used in non-carbonated reservoirs provided that irreducible water saturation can differentiate the rock types.

Acknowledgements The first two authors would like to thank National Iranian South Oil Company (NISOC) for providing data.

Open Access This article is distributed under the terms of the Creative Commons Attribution 4.0 International License (http://creativeco mmons.org/licenses/by/4.0/), which permits unrestricted use, distribution, and reproduction in any medium, provided you give appropriate credit to the original author(s) and the source, provide a link to the Creative Commons license, and indicate if changes were made. 


\section{References}

Archie GE (1952) Classification of carbonate reservoir rocks and petrophysical considerations. AAPG Bull 36(2):278-298

Amaefule JO, Altunbay M, Tiab D, Kersey DG, Keelan DK (1993) Enhanced reservoir description: using core and log data to identify hydraulic (flow) units and predict permeability in uncored intervals/wells. In: SPE annual technical conference and exhibition, Society of Petroleum Engineers

Askari AA, Behrouz T (2011) A fully integrated method for dynamic rock type characterization development in one of Iranian off-shore oil reservoir. J Chem Pet Eng Univ Tehran 45(2):83-96

Bize-Forest N, Baines V, Boyd A, Moss A, Oliveira R (2014) Carbonate reservoir rock typing and the link between routine core analysis and special core analysis. In: International symposium of the society of core analysts, pp 8-11

Ghadami N, Rasaei MR, Hejri S, Sajedian A, Afsari K (2015) Consistent porosity-permeability modeling, reservoir rock typing and hydraulic flow unitization in a giant carbonate reservoir. J Pet Sci Eng 131:58-69

Gomes JS, Ribeiro MT, Strohmenger CJ, Negahban S, Kalam MZ (2008) Carbonate reservoir rock typing - the link between geology and SCAL. In: Abu Dhabi International Petroleum Exhibition and Conference, Society of Petroleum Engineers

Lian PQ, Tan XQ, Ma CY, Feng RQ, Gao HM (2016) Saturation modeling in a carbonate reservoir using capillary pressure based saturation height function: a case study of the Svk reservoir in the $Y$ Field. J Pet Explor Prod Technolo 6(1):73-84

Mirzaei-Paiaman A, Saboorian-Jooybari H (2016) A method based on spontaneous imbibition for characterization of pore structure: application in pre-SCAL sample selection and rock typing. J Nat Gas Sci Eng 35:814-825

Mirzaei-Paiaman A, Ostadhassan M, Rezaee R, Saboorian-Jooybari H, Chen Z (2018) A new approach in petrophysical rock typing. J Pet Sci Eng 166:445-464

Moradi M, Moussavi-Harami R, Mahboubi A, Khanehbad M, Ghabeishavi A (2017) Rock typing using geological and petrophysical data in the Asmari reservoir, Aghajari Oilfield, SW Iran. J Pet Sci Eng 152:523-537

Mutina A, Bruyndonckx P (2012) Micro-CT/micro-XRF study of reservoir rocks: examination of technique applicability for core analysis. Micro-CT Meeting (Wallonia)

Noorddin H, Hossain ME, Sudriman SB, Sulaimani T (2011) Field application of a modified Kozney-Carmen correlation to characterize hydraulic flow unit. In: SPE/DGS Saudi Arabia section technical symposium and exhibition. Society of Petroleum Engineers

Riazi Z (2018) Application of integrated rock typing and flow units identification methods for an Iranian carbonate reservoir. J Pet Sci Eng 160:483-497

Shedid SA, Almehaideb RA (2002) A new approach of reservoir description of carbonate reservoirs. In: SPE International Petroleum Conference and Exhibition in Mexico, Society of Petroleum Engineers

Siddiqui S, Okasha TM, Funk JJ, Al-Harbi AM (2003) SCA2003-40: new representative sample selection criteria for special core analysis. In: International Symposium of the Society of Core Analysts

Siddiqui S, Okasha TM, Funk JJ, Al-Harbi AM (2006) Improvements in the selection criteria for the representative special core analysis samples. SPE Reservoir Eval Eng 9(06):647-653

Svirsky D, Ryazanov A, Pankov M, Corbett PW, Posysoev A (2004) Hydraulic flow units resolve reservoir description challenges in a Siberian Oil Field. In: SPE asia pacific conference on integrated modelling for asset management. Society of Petroleum Engineers

Tonietto SN, Smoot MZ, Pope M (2014) PS Pore Type Characterization and Classification in Carbonate Reservoirs

Ubani CE, Adeboye BY, Oriji BA (2012) Advances in coring and core analysis for reservoir formation evaluation. Pet Coal 54(1)

Publisher's Note Springer Nature remains neutral with regard to jurisdictional claims in published maps and institutional affiliations 